\title{
Islam dan Indonesia
}

\author{
Ruslana, ${ }^{1 \mathrm{a},}$ Fandy Adpen Lazzavietamsib, ${ }^{2 b^{*}}$, Nanda Winar Sagita ${ }^{3}$ \\ ${ }^{a}$ Universitas Syiah Kuala, Aceh \\ ${ }^{\mathrm{b}}$ STKIP PGRI Tulungagung, Tulungagung \\ ${ }^{c}$ SMA Negeri 6, Aceh Tengah \\ ${ }^{1}$ ruslan@unsyiah.ac.id ${ }^{2}$ fandyadpen@gmail.com ${ }^{3}$ nandawinarsagita@gmail.com \\ ${ }^{*}$ korespondensi penulis
}

\begin{abstract}
ABSTRAK
Kajian ini bertujuan mengurai perdebatan yang terjadi antara agama dan negara, dimana setiap agama mempunyai sikap yang berbeda dalam hubungan antara agama dan negara tersebut. Metode kajian dilakukan melalui studi pustaka atas penelitian yang berkaitan dengan persoalan tersebut. Melalui perspektif politik David Easton dan politik Islam kontemporer, secara garis besar terdapat dua arah dalam memandang agama Islam dan Negara Indonesia. Pertama, Islam merupakan agama yang monoteistik dan mencakup segala aspek kehidupan dan dalam rangka mengimplementasikan ajaran tersebut secara utuh, maka berdirinya negara Islam merupakan suatu keharusan. Kedua, Islam dan Indonesia sudah berkait dalam suatu prinsip dasar berbangsa dan bernegara yaitu Pancasila, bahkan jika dicermati sila satu Pancasila "Ketuhanan Yang Maha Esa", sila tersebut mengisyaratkan monoteistik. Dan apabila dibandingkan dengan agama lain konsep ketuhanan dalam agama Islam menganut kepercayaan kepada satu Tuhan (monoteis).
\end{abstract}

Kata kunci: Indonesia, Islam, Pancasila

\section{ABSTRACT}

This study aims to parse debate between religion and state, where each religion has a different attitude in the relationship between religion and the state. The method of the study carried out through a literature study on research related to the issue. Through David Easton's political perspective and contemporary Islamic politics, there are broadly two directions in viewing Islam and the Indonesian State. First, Islam is a monotheistic religion and encompasses all aspects of life, and in order to implement the teachings in full, the establishment of an Islamic state is a must. Secondly, Islam and Indonesia have been linked in a fundamental principle of nationhood and state, namely Pancasila, even if observed by the precepts of one Pancasila "Godhead of the Almighty", the precepts imply monotheism. And when compared to other religions, the concept of God in Islam embraces the belief in one God (monotheist).

Keywords: Indonesia, Islam, Pancasila

Copyright (C) 2019 Universitas Ahmad Dahlan, All Right Reserved

\section{PENDAHULUAN}

Sebelum Indonesia merdeka tanah air dikenal dengan Nusantara (dalam bahasa sansekerta) merupakan suatu wilayah dengan 17.504 pulau (Wikipedia, 2019a) yang tersebar dari Sabang sampai Merauke. Pada masa kerajaan mayoritas penduduk memeluk agama Hindu dan Budha sampai pada akhirnya Islam masuk ke Nusantara melalui jalur perdagangan. Islam tersebar ke seluruh Nusantara melalui strategi dakwah Sunan Gresik yang lebih terorganisir dan bertahan dari generasi ke generasi yang oleh masyarakat muslim Indonesia lebih dikenal dengan Wali Songo (Hatmansyah, 2017; Suparjo, 1970; Syafrizal, 2015). Islam kini telah menjadi agama mayoritas penduduk di Nusantara atau Indonesia yaitu sebanyak $87,2 \%$ dari total jumlah penduduk di Indonesia (Wikipedia, 2019b). Apabila dibandingkan penyebaran Islam pada masa khalifah khulafaur rasyidin yang melalui jalan peperangan, Islam masuk ke Indonesia secara damai. Strategi dakwah walisongo yang mengenalkan Islam kepada penduduk di Nusantara secara damai berdampak pada sinkretisasi budaya dan tradisi sekitar dengan Islam, sehingga setiap daerah menampilkan karakteristik keislamannya sendiri-sendiri.

Islam telah mendampingi bangsa Indonesia dari masa ke masa sehingga melekat dan menjadi bagian dari kehidupan mayoritas penduduk Indonesia. Ketika penjajah dari Portugis memasuki tanah air pada awal abad ke-16 M (Ricklefs, 2001), Islam telah tersebar di Nusantara. Hal ini bisa dibuktikan dengan sistem pemerintahan kesultanan yang tersebar di beberapa daerah di Nusantara. Sistem pemerintahan kesultanan merupakan manifestasi ajaran Islam dalam kehidupan bernegara. Terwujudnya sistem pemerintahan tersebut tidak terlepas dari strategi dakwah para Wali Songo diantaranya yaitu dengan menikahi putri raja sehingga memper-lancar ajaran agama Islam diterima dan dianut oleh mayoritas 
penduduk dalam suatu kerajaan tersebut (Hayat, 2014; Mudjiono, 2007).

Pergumulan Islam di Nusantara pasca dakwah Wali Songo diteruskan oleh raja-raja atau sultan dan ulama yang merupakan murid dari Wali Songo yang selalu terhubung dengan jaringan Islam di Wilayah jazirah Arab. Pada masa pra kemerdekaan Indonesia, umat Islam bersatu dan mempunyai pemahaman yang sama dalam mentransformasikan ajaran agama Islam dalam kehidupan sehari-hari. Mengingat pada masa penjajahan keadaan masyarakat sangat memprihatinkan. Masalah utama bagi umat Islam pada masa itu adalah mempertahankan hidup. Sampai pada akhirnya pada tahun 1945 bangsa Indonesia memproklamasikan kemerdekaannya. Dari tahun 1945 sampai pada masa kini Islam masih bergulat dengan negara Indonesia, pergulatan tersebut dapat dilihat dari beberapa periode yang oleh Ismail (2017) diklasifikasikan menjadi 5 periode, yaitu pada periode BPUPKI, periode demokrasi terpimpin, periode $\mathrm{P} 4$, periode azas tunggal Pancasila babak pertama dan kedua. Pergulatan Islam dan Negara Indonesia didasari atas cara pandang umat Islam dalam memahami Islam itu sendiri yang setiap cara pendang tersebut mempunyai dasar legalitas Islam.

Cara memandang Islam secara berbeda berdampak pada implementasi ajaran agama Islam dalam kehidupan sehari-hari juga berbeda, diantaranya dalam kehidupan politik warga negara. Perbedaan tersebut bertahan sampai periode saat ini yang diperparah dengan fenomena ketegangan antar sesama umat Islam akibat penerapan ajaran agama Islam dalam kehidupan sehari-hari. Pasca reformasi yang membuka kebebasan kehidupan politik warga negara berpengaruh pada masuk dan menyebarnya aliran Islam yang bermacam-macam jenis dan bentuknya. Setiap aliran Islam tersebut mempunyai visi yang berbeda sebagai cita-cita bersama dalam meneguhkan ajaran agama Islam melalui doktrin aliran tersebut. Di antara aliran tersebut terdapat aliran Islam yang memperjuangkan terwujudnya negara Islam Indonesia. Artinya pergulatan Islam dan Negara Indonesia belum selesai sejak lahirnya negara Indonesia. Persoalan tersebut dibuktikan dengan semakin bertambah-nya pengikut organisasi kemasyarakatan Islam Hizbut Tahrir (HT), yang secara masif dan siste-matis masuk kedalam berbagai lembaga strategis di Indonesia (Wiwoho, 2017). Sementara penduduk Indonesia minoritas adalah umat ber-agama Kristen Katolik maupun Protestan, Hindu, Budha, dan Konghucu. Sesuai makna Islam itu sendiri yang berasal dari kata dasar salam berarti kedamaian, maka seharusnya Islam merupakan agama yang mendamaikan bagi sesama manusia, sehingga mayoritas sudah seharusnya melindungi minoritas.

Bermula dari persoalan cara memandang penerapan ajaran Islam di Indonesia tersebut sampai saat ini pemahaman antara agama dan Negara Indonesia belum tuntas untuk diuraikan. Fenomena organisasi HT tersebut memicu beberapa pertanyaan fundamental dalam kehidupan berbangsa dan bernegara di Indonesia. Di antaranya yaitu apakah persoalan agama Islam dan negara Indonesia sudah selesai? Bagaimana relasi agama Islam dan negara Indonesia? Dan siapakah yang seharusnya menyelesaikan persoal-an tersebut? Pertanyaan tersebut merupakan sebagian dari berbagai pertanyaan implikasi dari Islam dan Indonesia yang harus dijawab sehingga menjadi pemahaman kolektif atas konsep kewarganegaraan Indonesia yang mayoritas adalah penganut agam Islam.

\section{METODE}

Metode yang digunakan dalam mengkaji Islam dan Indonesia yaitu melalui studi pustaka melalui literatur-literatur yang relevan dengan kajian ini. Literatur pertama yaitu dari hasil penelitian yang dilakukan oleh para akademisi, literatur kedua yaitu melalui artikel ilmiah yang dimuat dalam jurnal maupun proceeding seminar nasional maupun internasional. Literatur ketiga yaitu dari buku referensi yang terkait dengan kajian Islam dan Indonesia ini (Raharjo \& Winarko, 2014). Dari literatur yang telah diklasifikasi tersebut selanjutnya diringkas sehing-ga ditemukan subtansi dari artikel. Pada tahap berikutnya yaitu menganalisis artikel untuk menelaah lebih lanjur subtansi artikel agar diperoleh pemahaman secara utuh dan mendalam dari artikel tersebut. Tahap terakhir dari studi pustaka yaitu menafsirkan konsep dan teori dari artikel tersebut (Wahono, 2016).

Langkah-langkah yang digunakan dalam studi pustaka unttuk mengkaji Islam dan Indo-nesia meliputi mengidentifikasi topik penelitian, membaca asbtrak hasil penelitian Islam dan Indonesia. Membuat catatan hasil bacaan, membuat ringkasan literatur, menyusun konsep dan teori yang berkaitan dengan Islam dan Indonesia secara tematis, merumuskan pandangan berkait-an dengan topik kajian agar diperoleh konsep baru mengenai Islam dan Indonesia.

\section{HASIL DAN PEMBAHASAN}

Agama merupakan ajaran yang memuat tata aturan hubungan manusia dengan Tuhan secara vertikal maupun horizontal (Dion, 2014). Di berbagai belahan dunia berkembang berbagai macam keyakinan dan kepercayaan yang pada 
akhirnya membentuk suatu sistem keyakinan sebagai landasan hidup manusia. Sedangkan Negara adalah organisasi tertingi dengan sistem pemerintahan yang sah di suatu wilayah yang ditempati oleh sekelompok manusia (Huda, 2007). Agama merupakan sistem keyakinan yang terdiri dari simbol agama yang mengisyaratkan identitas dari agama, bersifat dogmatis, praktik keagamaan, umat pemeluk agama. Seringkali setiap orang beragama dikarenakan pengaruh ajaran agama orang tua kepada anaknya yang ditransformasikan melalui pendidikan di keluar-ga. Maka muncul suatu pertanyaan mengenai kelahiran agama dan budaya. Apakah manusia berbudaya terlebih dahulu baru lahir agama atau sebaliknya budaya lahir karena agama yang dianut manusia. Terlepas dari perdebatan tersebut kedua bidang yaitu agama dan budaya mempunyai subyek dan objek yang sama yaitu manusia. Agama merupakan manifestasi keyakinan manusia akan kekuatan supernatural yang menciptakan dari segala yang tercipta, sehingga muncul konsp makro kosmos dan mikro kosmos dalam diri manusia dan alam semesta. Sebaliknya dengan pemahaman tersebut terdapat pemahaman lain yang menyatakan bahwa agama adalah ekspresi manusia atas perasaan yang kuat terhadap suatu simbol yang pada akhirnya membentuk suatu tatanan ritus yang unik (Pals, 2012, hal. 341). Di luar pemahaman pada agama tersebut terdapat ketidakyakinan terhadap agama. Semua pemahaman tersebut ada pada diri manusia yang diimplementasikan dalam kehidupan seharihari.

Negara terhubung dengan Agama yaitu dalam fungsinya sebagai penjamin atas terlaksananya hak dan kewajiban manusia secara aman dan nyaman melalui pengaturan dan penertiban. Dalam fungsi tersebut setiap manusia yang merupakan bagian dari negara sehingga disebut sebagai warga negara dapat mengimple-mentasikan pemahaman akan agama dalam kehidupan sehari-hari secara bebas. Di sisi lain agama merupakan sumber nilai dari kewarga-negaraan, artinya nilai kewarganegaraan pada dasarnya bersumber dari nilai agama. Di Indonesia mayoritas penduduk memeluk agama Islam yang menganut keyakinan kepada satu Tuhan (monoteisme). Nilai-nilai dalam Islam seringkali menjadi landasan dalam kehidupan berbangsa dan bernegara. Salah satunya yaitu terdapat pada sila ke-1 Pancasila yaitu Ketuhanan Yang Maha Esa. Makna Esa yang berarti bersifat tunggal sesuai dengan konsep monoteisme dalam Islam yang meyakini ke-Esa-an Allah SWT. Dari pengertian tersebut dapat disimpulkan bahwa persolan Agama dan Negara tidak dapat dipertentangkan mengingat keduanya melekat kepada setiap diri manusia yang bersifat monopluralistik, artinya manusia sebagai umat dari agama tertentu sekaligus juga manusia sebagai warga negara. Namun dalam praktek kehidupan bernegara, antara Agama dan Negara ada yang memisahkan namun juga sebaliknya mempersatukan keduanya.

Secara etimologis Islam berasal dari kata dasar salam yang bermakna kedamian, kosakata Islam sendiri berasal dari jazirah Arab yang diyakini sudah ada sejak sebelum keberadaan Nabi Muhammad. Berdasarkan perkembangan agama Islam dari zaman Nabi Muhammad SAW dibagi menjadi beberapa periode yang menunjuk-kan perkembangan ajaran agama Islam dari masa ke masa. Periodesasi tersebut dibagi menjadi, pertama pada masa Nabi Muhammad SAW masih hidup, kedua sepeninggal Nabi Muhammad SAW, yaitu masa kekhalifahan empat sahabat Nabi yaitu Abu Bakar As Siddiq, Umar Bin Khatab, Usman Bin Affan, dan Ali Bin Abi Thalib, ketiga pada masa tabi'in atau sepeninggal sahabat nabi, keempat pada masa tabi'in tabi'in, dan terakhir kelima pada masa ulama.

Berdasarkan klasifikasi periode Islam dari awal muncul sampai ke Indonesia, maka periode Islam di Indonesia yaitu masuk dalam periode ulama. Agama Islam diturunkan kepada utusan Allah SWT yang terakhir yang merupakan penutup dari utusan-utusan sebelumnya yaitu Nabi dan Rosul. Utusan Allah yang diberikan wahyu untuk dirinya sendiri maupun orang lain yang seiman disebut Nabi, sedangkan utusan Allah SWT yang diberikan wahyu untuk menuntun orang kafir (berlainan iman) agar beriman kepada Allah SWT dan membawa suatu tatanan baru (syariat) disebut Rosul. Seorang Rosul pasti seorang Nabi namun seorang Nabi belum tentu seorang Rosul.

Nabi dan Rosul diturunkan pada masa yang berbeda dari zaman Nabi Adam a.s. sampai dengan terakhir penutup Nabi dan Rosul yaitu Muhammad SAW, yang artinya tidak ada lagi Nabi dan Rosul setelahnya. Nabi Muhammad SAW membawa ajaran agama Islam sebagai penutup dari ajaran agama yang diturunkan Allah SWT kepada Rosul sebelumnya yaitu agama nasrani yang saat ini lebih dikenal sebagai kristen dengan kitab injil dan Nabi Isa a.s. sebagai Rosulnya. Sebelum nasrani terdapat agama yahudi dengan kitab Taurot dan Nabi Musa a.s. sebagai Rosulnya. Agama Islam menyempurnakan agama sebelumnya baik dari segi tatanan hidup maupun hubungan manusia dengan Tuhannya. Islam sendiri secara etimologis memiliki makna "aslama, uslimu, islaman" yang artinya berserah diri kepada Allah SWT. Islam muncul sekitar abad ke-6 $M$ melalui Nabi Muhammad SAW yang lahir pada tahun $571 \mathrm{M}$ dari Abdullah dan Aminah. 
Islam masuk ke Indonesia melalui para musafir yang sekaligus juga pedagang dari Gujarat India, Persia, Cina, dan dari Makkah, maka teori masuknya Islam di Indonesia didasarkan pada asal muasal musafir muslim tersebut. Di antara beberapa teori yang paling tua dari segi usia yaitu teori Makkah yang menyampaikan bahwa Islam masuk ke Indonesia sejak aba ke-7 M. Teori ini didukung oleh Buya Hamka melalui seminar yang diselenggarakan pada tahun 1963. Teori tersebut menyatakan Islam masuk ke Nusantara sudah sejak tahun pertama hijriah atau abad $7 \mathrm{M}$ dengan bukti bahwa pada masa itu sudah terdapat jalur pelayaran internasional yang menghubungkan antara Dinasti Tang di Cina, Sriwijaya di Asia Tenggara dan Bani Umayyah Asia Barat. Berdasarkan teori tersebut berarti hubungan Islam dengan Indonesia (Nusantara waktu itu) sudah terjadi sejak abad ke-7 $M$ pada kekhalifahan Sayidina Ali bin Abi Thalib (Ghofur, 2011).

Pada abad ke-7 M Indonesia yang pada waktu itu lebih dikenal dengan sebutan Nusantara karena Nusa yang berada di antara perairan, masyarakat sudah mempunyai kebudayaan yang cukup maju. Hal ini dibuktikan dengan keber-adaan sebuah pemerintahan yang mencakup, kamboja, Thailand dan Malaysia dan Singapura. Pemerintahan tersebut merupakan kerajaan Sriwijaya yang berpusat di sekitar Palembang dekat sungai Musi. Agama yang berkembang di kerajaan tersebut yaitu agama Budha yang dibuktikan dengan pernyataan pendeta Budha dari Tiongkok yang singgah ke Sriwijaya untuk belajar bahasa sansekerta. Pada periode berikutnya pendeta budha bernama I-Tsing tersebut datang kembali ke Sriwijaya untuk menerjemahkan kitab agama budha dari bahasa sansekerta ke bahasa Tiongkok. Pada masa itu pedagang tidak hanya dari Tiongkok namun juga dari Persia dan Arab. Sehingga Islam masuk ke Indonesia tidak melalui jalan kekerasan seperti masuknya Islam di beberapa negara di Eropa, sebaliknya justru Islam masuk melalui perdamaian.

Secara historis Islam berabad-abad berada di Indonesia sudah 14 abad, namun tidak lantas secara kebudayaan berubah secara radikal mejadi seperti budaya di jazirah arab. Islam Indonesia mempunyai corak tersendiri sesuai dengan karakteristik ke-Indonesia-an yang oleh beberapa pakar diformulasikan menjadi Islam Nusantara. Formulasi tersebut bukan merupakan sebuah aliran dalam agama Islam, namun karakteristik yang menunjukkan model Islam di Indonesia (Luthfi, 2017). Namun formulasi tersebut masih diperdebatkan dikalangan sarjana muslim di Indonesia. Setelah kemerdekaan Indonesia pada 17 Agustus 1945, relasi Islam dan Indonesia terlihat melalui peran para tokoh muslim di Indonesia dari mendirikan negara sampai membangun negara Indonesia.

Peran tokoh muslim Indonesia pada sidang BPUPKI terbagi menjadi dua golongan yaitu golongan nasionalis muslim dan golongan nasionalis netral agama. Golongan nasionalis muslim terdiri dari KH. Mas Mansur, Abdul Kahar Muzakhir, Ki Bagus Hadikusumo, KH. Masjkur, KH.A. Wahid Hasjim, Abikusno Tjokrosujoso, H. Agus Salim, Sukiman Wirjosandjojo, KH. A. Sanusi, dan KH. Abdul Halim. Prosentase tokoh nasionalis muslim yaitu $20 \%$ dan $80 \%$ dari tokoh nasional netral agama. Relasi Islam dan Indonesia terlihat pada musyawarah dalam sidang BPUPKI ketika menentukan bentuk dari negara Indonesia. Abdul Kahar Muzakkir menyampaikan bahwa 53 anggota BPUPKI memlih bentuk Republik sedangkan 7 anggota memilih bentuk kerajaan (Ismail, 2017). Kesepakatan mayoritas peserta sidang BPUPKI tersebut merupakan jawaban pertama atas relasi Islam dan Indonesia. Jika dikaitkan dengan bentuk negara, Islam memiliki konsep kenegaraan yang saat ini diperdebatkan oleh para sarjana muslim Indonesia. Konsep tersebut terdiri dari darul Islam (negara Islam) dan darussalam (negara damai), konsep pertama didasarkan pada pemaknaan QS An Nur ayat 55 yang diuraikan ke dalam suatu sistem pemerintahan khalifah (Hosen, 2019a), sedangkan konsep kedua dilandaskan pada terminologi khalifah yang digunakan di dalam Al Quran tidak merujuk pada makna sistem pemerintahan, namun potensi setiap manusia untuk menjadi pemimpin di muka bumi (Hosen, 2019b). Darul Islam atau negara Islam merupakan konsepsi atas sistem pemerintahan yang menuntut terwujudnya sebuah teokrasi atas dasar ajaran agama Islam. Persetujuan para peserta sidang BPUPKI akan bentuk negara Indonesia menjadi sebuah negara Republik diuji dengan munculnya gerakan Negara Islam Indonesia oleh seorang politisi muslim yaitu Kartosoewirjo pada tahun 1949 (Ausop, 2009; Azra, 2014). Gerakan tersebut memicu gerakan Negara Islam Indonesia di beberapa daerah lainnya, seperti di Aceh melalui Daud Beureueh yang memproklamirkan bahwa Aceh merupakan bagian dari Negara Islam Indonesia pada tahun 1953. Di Kalimantan Selatan pemberontakan dipimpin oleh Ibnu Hadjar pada tahun 1950, dan di Jawa Tengah dipimpin oleh Amir Fattah. Di Sulawesi Selatan dipimpin oleh Kahar Muzakkar pada tahun 1953 menyatakan diri sebagai bagian dari Negara Islam Indonesia. Pada akhirnya pemberontakan dalam upaya pendirian Negara Islam Indonesia berhasil ditumpas pada tahun 1965 dengan ditembaknya Kartosoewirjo. 
Di sisi lain dari perjuangan umat muslim di Indonesia dalam mendirikan Negara Islam Indonesia terdapat umat muslim yang membela Negara Kesatuan Republik Indonesia dengan Pancasila sebagai dasar negara. Umat muslim yang membela Pancasila juga menghadapi perso-alan yang sama peliknya dengan sesama muslim yang menganut faham komunis. Persoalan tersebut berimplikasi pada pembantaian para kyai di Madiun pada tahun 1948, ketegangan sosial akibat tragedi madiun pada akhirnya memicu terjadinya tragedi 1965 (Wejak, 2018). Umat muslim yang menganut paham komunis dan tergabung dalam Partai Komunis Indonesia (PKI) juga menginginkan negara Indonesia dijadikan sebagai negara komunis. Indonesia sebagai negara republik pada awal kemerdekaan di uji oleh berbagai masalah yang mengungkit kembali sebuah bentuk pemerintahan.

Benturan antara Islam dan Indonesia meruncing kembali pascareformasi kran kebebas-an berpendapat dibuka. Implikasi dari era refor-masi yaitu menguatnya berbagai golongan Islam yang tergabung dalam oragnisasi kemasyarakatan (ormas) Islam. Bahkan secara terang-terangan terdapat ormas Islam yang meneguhkan visinya untuk mengganti bentuk pemerintahan republik menjadi negara Islam Indonesia. Berbagai aliran dalam Islam mewarnai ormas tersebut, dari yang lembut sampai yang radikal (Laisa, 2014). Radikal disini yaitu cara berpikir mengenai implementasi syariat Islam dalam kehidupan sehari-hari. Persoalan tersebut tentunya berdampak pada umat Islam itu sendiri. Apabila dibandingkan dengan pra kemerdekaan bangsa Indonesia, umat Islam Indonesia saat ini lebih sejahtera. Sehingga sudah semestinya prosentase pemeluk Islam di Indonesia bertambah. Namun terjadi sebaliknya, data dari beberapa lembaga peneliti dan pengkaji pertumbuhan Islam di Indonesia memperlihatkan penurunan jumlah penganut agama Islam. Data tersebut pernah disampaikan oleh Ketua MUI tahun 2014 Din Syamsudin yang menyebutkan bahwa pada tahun 1990 jumlah umat Islam di Indonesia yaitu $87,6 \%$, pada tahun 2000 meningkat menjadi $88,2 \%$, sedangkan pada tahun 2010 turun menjadi 85,1\% (Hamid, 2016). Penurunan jumlah umat Islam tersebut seharusnya menjadi evaluasi bagi setiap umat Islam untuk lebih menebarkan kedamaian melalui berbagai hal termasuk cara dakwah yang baik dan santun. Kedamaian akan tercipta apabila setiap manusia saling memberikan rasa yang menenteramkan.

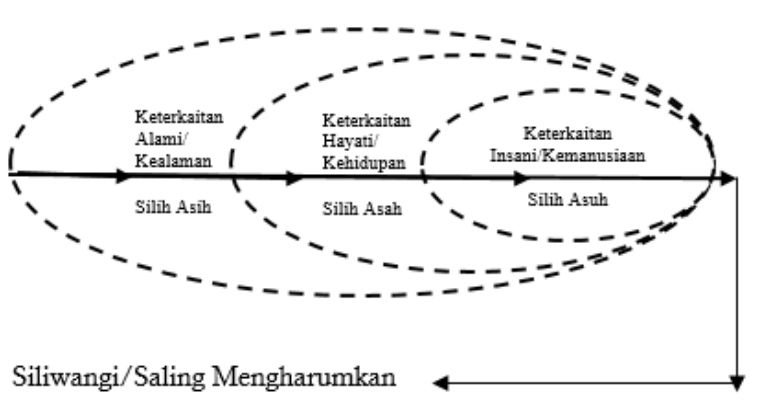

Gambar 1 Keterkaitan antara manusia Sumber: Purwasasmita (2015)

Secara umum Purwasasmita (2015) menjelaskan bahwa ada keterkaitan antara manusia yang satu dengan manusia yang lain sehingga saling mengharumkan dan menenteram-kan karena yang diberikan kepada sesama manusia lainnya adalah perasaan bukan rasionalitas kebenaran.

Islam dan Indonesia terhubung oleh manusia yang merupakan umat Islam dan di saat yang sama juga sebagai warga negara Indonesia. Konsep manusia seperti itu secara komprehensif oleh Sunarjo Wreksosuharjdo digambarkan sebagai manusia Pancasila sebagai berikut.

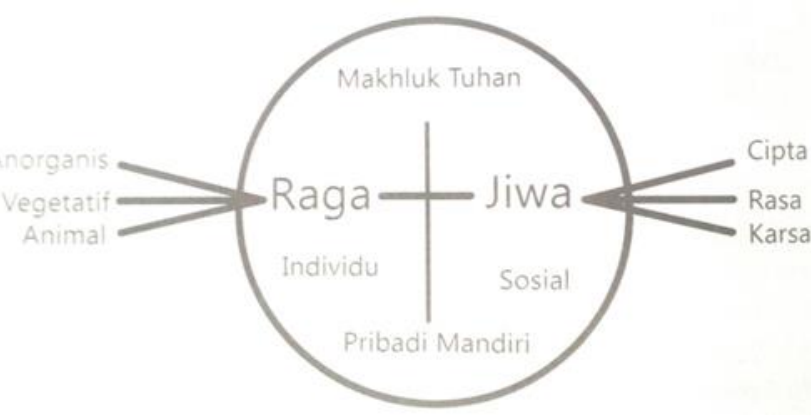

Gambar 2 Manusia Pancasila

Sumber: Wreksosuhardjo (2014)

Manusia Pancasila adalah manusia yang diilhami oleh nilai-nilai dalam sila Pancasila yang secara hierarkis terkait satu dengan yang lainnya, artinya sila satu melandasi sila ke-2, ke-3, ke-4, dan ke-5. Sedangkan sila ke-2 dilandasi sila ke-1 dan melandasi sila ke-3, ke-4, ke-5, begitu seterusnya setiap sila yang ada diatasnya melandasi sila yang ada dibawahnya (Kaelan, 2013). Lebih lanjut sila ke-1 pancasila mengisyaratkan bahwa setiap warga negara Indonesia merupakan manusia yang mempunyai keyakinan kepada Tuhan, namun disaat yang sama Pancasila merupakan sistem nilai bukan merupakan agama yang merupakan sistem keyakinan. Sehingga sila ke-1 Pancasila berarti merupakan sikap religiusitas warga negara Indonesia (Amien, 2006; Hidayatullah, 2017).

Persoalan Islam dan Indonesia pasca reformasi yang patut dicermati adalah khasus 
pembubaran ormas HTI yang secara materiil benar karena secara langsung ormas tersebut menyatakan pendiriannya untuk mewujudkan visi politik mendirikan Negara Islam Indonesia. Sehingga mengancam keutuhan Negara Republik Indonesia. Seperti halnya gerakan pada masa Kartosoewirjo yang mencoba mengubah negara Republik Indonesa menjadi Negara Islam Indonesia (NII). Namun secara formal prosedural pembubaran ormas tersebut kurang tepat karena tanpa melalui proses peradilan terlebih dahulu. Pada akhirnya sesuatu yang benar seharusnya juga dilakukan dengan cara yang benar. Sehingga lingkungan sebagai pengendali sistem politik menjadi lebih kondusif.

Relasi Islam dan Indonesia dalam praktik kehidupan warga negara lebih lanjut dijelaskan oleh KH Abdurrahman Wahid (Wahid, 1992, 2006), bahwa keyakianan setiap warga negara kepada agama yang dipeluknya merupakan manifestasi eskatologi setiap manusia kepada Tuhan-nya. Sedangkan dalam kehidupan bernegara harus didudukkan pada pemahaman dan kesepakatan bahwa setiap individu berhak atas keyakinannya, untuk itu tidak dibenarkan warga negara berhak atas keyakinan warga negara lain. Dalam hal ini negara harus menjaga ranah spiritual setiap warga negara, agar menjalankan keyakinannya dengan nyaman, tenteram dan damai. Sehingga dalam pengertian tersebut negara Indonesia bukan negara sekuler namun juga bukan negara teokrasi. Untuk itu Pancasila sila ke-1 merupakan manifestasi atas relasi Islam dan Indonesia yang dibingkai oleh para pendiri negara Indonesia sebagai dasar hidup berbangsa dan bernegara. Relasi Islam dan Indonesia termuat dalam sila Ketuhanan Yang Maha Esa Pancasila, yang menjadi dasar bagi silasila berikutnya.

\section{KESIMPULAN}

Islam merupakan sistem keyakinan, sedangkan Indonesia merupakan negara yang di dalamnya memuat sistem politik. Manusia sebagai unsur utama sebuah negara dan sebagai warga negara ada yang mendukung dan menuntut suatu sistem politik yang menurutnya lebih baik. Ketika tuntutan keluar dari kaidah fundamental negara, pemerintah berperan dalam mengolah tuntutan tersebut agar menjadi keputusan yang mendamaikan berbagai pihak. Relasi Islam dan Indonesia pada kasus pembubaran ormas Islam HTI secara materiil barangkali benar, namun secara formil pemerintah kurang tepat. Dampaknya yaitu pada tuntutan atau dukungan yang akan semakin meluas terhadap ormas tersebut yang berakhir pada visi negara Islam Indonesia.

\section{DAFTAR PUSTAKA}

Amien, M. (2006). Causa Materialis Pancasila Menurut Notonagoro. Jurnal Filsafat. https://doi.org/10.22146/jf.23212

Ausop, A. Z. (2009). Gerakan NII Kartosoewirjo (KW IX). Jurnal Sosioteknologi, 8(16), 531542.

Azra, A. (2014). Kartosuwiryo dan NII: Kajian Ulang. Studia Islamika, 21(1), 175-182.

Dion, A. P. (2014). Agama. Academia.edu.

Ghofur, A. (2011). Tela'ah Kritis Masuk dan Berkembangnya Islam di Nusantara. Jurnal Ushuluddin, $17(2)$. https://doi.org/10.24014/JUSH.V17I2.689

Hamid, A. (2016). Mengapa Jumlah Umat Islam di Indonesia Menurun? www.nu.or.id.

Hatmansyah. (2017). Strategi dan Metode Dakwah Walisongo. Al-Hiwar : Jurnal Ilmu dan Teknik Dakwah, 3(5), 10-17. https://doi.org/10.18592/alhiwar.v3i5.1193

Hayat. (2014). Strategi dakwah NU dalam membangun mental dan karakter masyarakat. Jurnal Walisongo.

Hidayatullah, S. (2017). Notonagoro dan Religiusitas Pancasila. Jurnal Filsafat. https://doi.org/10.22146/jf.23214

Hosen, N. (2019a). Benarkah Allah Menjanjikan Kembalinya Khilafah? | Gus Nadirsyah Hosen. nadirhosen.net.

Hosen, N. (2019b). Istilah Khilafah Tidak Ada Dalam Al-Qur'an I Gus Nadirsyah Hosen. nadirhosen.net.

Huda, N. (2007). Hukum Tata Negara Indonesia. Jakarta: Raja Grafindo Persada.

Ismail, F. (2017). Panorama Sejarah Islam dan Politik di Indonesia; Sebuah Studi Komprehensif (A. F. Muhammad (Ed.); 1 ed.). IRCiSoD.

Kaelan. (2013). Negara Kebangsaan Pancasila (1 ed.). Paradigma.

Laisa, E. (2014). Islam dan Radikalisme. Islamuna: Jurnal Studi Islam, 1(1), 1-18. https://doi.org/10.19105/islamuna.v1i1.554

Luthfi, K. M. (2017). Islam Nusantara: Relasi Islam dan Budaya Lokal. SHAHIH : Journal of Islamicate Multidisciplinary. https://doi.org/10.22515/shahih.v1i1.53

Mudjiono, Y. (2007). Strategi dakwah wali songo dalam perspektif ilmu komunikasi. Jurnal 
Ilmu Dakwah Vol. 14 No. 1 April 2007.

Pals, D. L. (2012). Seven Theories of Religion (II). IRCiSoD.

Purwasasmita, M. (2015). Fenomenologi Nilai. Departemen Pendidikan Kewarganegaraan.

Raharjo, S., \& Winarko, E. (2014). Klasterisasi, klasifikasi dan peringkasan teks berbahasa indonesia. Kommit 2014.

Ricklefs, M. C. (Merle C. (2001). A history of modern Indonesia since c. 1200. Stanford University Press.

Suparjo. (1970). Islam dan Budaya: Strategi Kultural Walisongo dalam Membangun Masyarakat Muslim Indonesia. KOMUNIKA: Jurnal Dakwah dan Komunikasi, 2(2), 178-193. https://doi.org/10.24090/komunika.v2i2.10 0

Syafrizal, A. (2015). Sejarah Islam Nusantara. Islamuna: Jurnal Studi Islam, 2(2), 235-253. https://doi.org/10.19105/islamuna.v2i2.664

Wahid, A. (1992). Pancasila sebagai Ideologi dalam Kaitannya dengan Kehidupan Beragama dan Berkepercayaan Terhadap Tuhan yang Maha Esa. In O. Oesman (Ed.), Pancasila Sebagai Ideologi: Dalam Berbagai Bidang Kehidupan Bermasyarakat, Berbangsa, dan Bernegara. BP-7.

Wahid, A. (2006). Islamku, Islam Anda, Islam Kita : Agama Masyarakat Negara Demokrasi. In The Wahid Institute. https://doi.org/10.1017/CBO978110741532 4.004

Wahono, R. S. (2016). Systematic Literature Review: Pengantar, Tahapan Dan Studi Kasus. In Slr.

Wejak, J. L. (2018). Narasi radikalisme dan ketakutan (Radicalism narration and fear). Jurnal Ledalero, 17(1), 77-94. https://doi.org/10.31385/j1.v17i1.128.77-94

Wikipedia. (2019a). Daftar pulau di Indonesia menurut provinsi - Wikipedia bahasa Indonesia, ensiklopedia bebas. wikipedia.

Wikipedia. (2019b). Islam menurut negara. Website.

Wiwoho, B. (2017). Sepak Terjang dan Akhir Hikayat Hizbut Tahrir Indonesia. www.cnnindonesia.com.

Wreksosuhardjo, S. (2014). Filsafat Pancasila secara Ilmiah dan Aplikatif(1 ed.). Andi Offset. 